\title{
Adherence to Social Distancing Measures for Controlling COVID-19 Pandemic: Successful Lesson From Vietnam
}

\author{
Hoang-Long Vo ${ }^{1}$, Hao Anh Si Nguyen ${ }^{1}$, Khanh Ngoc Nguyen ${ }^{1}$, Huong Lan Thi Nguyen ${ }^{2,3 *}$, \\ Hien Thi Nguyen ${ }^{2,3}$, Long Hoang Nguyen ${ }^{4}$, Giang Thu Vu ${ }^{5}$ and Huong Thi Le ${ }^{1}$ \\ ${ }^{1}$ Institute for Preventive Medicine and Public Health, Hanoi Medical University, Hanoi, Vietnam, ${ }^{2}$ Institute for Global Health \\ Innovations, Duy Tan University, Da Nang, Vietnam, ${ }^{3}$ Faculty of Nursing, Duy Tan University, Da Nang, Vietnam, ${ }^{4}$ Institute of \\ Health Economics and Technology, Hanoi, Vietnam, ${ }^{5}$ Center of Excellence in Evidence-based Medicine, Nguyen Tat Thanh \\ University, Ho Chi Minh City, Vietnam
}

Keywords: COVID-19, SARS-CoV-2, adherence, social distancing, Vietnam

OPEN ACCESS

Edited by:

Jongnam Hwang,

Wonkwang University, South Korea

Reviewed by:

Enahoro Iboi,

Spelman College, United States

Nguyen C. Tat,

Griffith University, Australia

*Correspondence:

Huong Lan Thi Nguyen nguyentlanhuong5@duytan.edu.vn

Specialty section:

This article was submitted to

Health Economics,

a section of the journal

Frontiers in Public Health

Received: 31 July 2020 Accepted: 07 September 2020 Published: 16 November 2020

Citation:

Vo H-L, Nguyen HAS, Nguyen KN, Nguyen HLT, Nguyen HT, Nguyen LH, Vu GT and Le HT (2020) Adherence to

Social Distancing Measures for Controlling COVID-19 Pandemic:

Successful Lesson From Vietnam

Front. Public Health 8:589900.

doi: 10.3389/fpubh.2020.589900
Social distancing measure has been considered an effective policy response across nations to mitigate the spread of the COVID-19 pandemic (1). Given the matter that SARS-CoV-2 transmits via close contact, social distancing requires individuals to keep a distance of at least 6 feet from people who do not belong to their households (1). Vietnam has achieved initial results in flattening the curve and slowing the spread of COVID-19 transmission in the community, which is mainly attributable to a high-level adherence of Vietnamese with social distancing measures, accompanied with contact tracing, mass testing, and mandatory isolation (2).

Social distancing measure had been implemented in Vietnam, a country having a long borderline with China, from a very early phase as one of the precautionary measures since the first case was detected on 22 January (Figure 1). On 31 January 2020, the Prime Minister issued the Directive 06/CT-TTg (3) to enforce banning, suspending, or narrowing traditional festivals to limit the crowds of people, as well as temporary disclosure of schools and universities, and promoting the use of face masks in public locations. After controlling successfully the first wave of the COVID19 outbreak with nearly 20 days without reported cases, on 18 March 2020, Vietnam confronted a great challenge when new local cases with unknown causes of transmission were detected in Hanoi, a metropolitan of Vietnam. Until 31 March 2020, 213 new cases were confirmed, and most of them were asymptomatic. During this period, more strict social distancing measures were implemented, including banning crowds of people with more than ten people as well as requesting closure of nonessential places such as educational institutions or entertainment places, restricting the intercity and intracity movement. On 31 March 2020, the Directive 16/CT-TTg was issued which required nationwide social distancing implementation in 15 days. During this period, 59 new cases of COVID-19 were identified (4); however, since 17 April, Vietnam had confirmed no community transmission despite extensive testing. On 23 April, the Vietnam Government decided to loosen the national lockdown and issued the Directive 19/CT-TTg on 24 April about COVID-19 prevention and control strategies in the "new normal" condition, in which social distancing played a major role (5).

The high compliance of Vietnamese with social distancing measures can be explained in multiple perspectives. In terms of the leadership, initially, after the detection of the first case, the Vietnam government rapidly formed the Task Force for the COVID-19 epidemic under the direction of the Vice Prime Minister. The Task Force members encompassed leaders of ministries, localities, and press representatives, aiming to develop national COVID-19 preventive and control measures. Previous experiences with Severe Acute Respiratory Syndrome (SARS) and H1N1 epidemics 


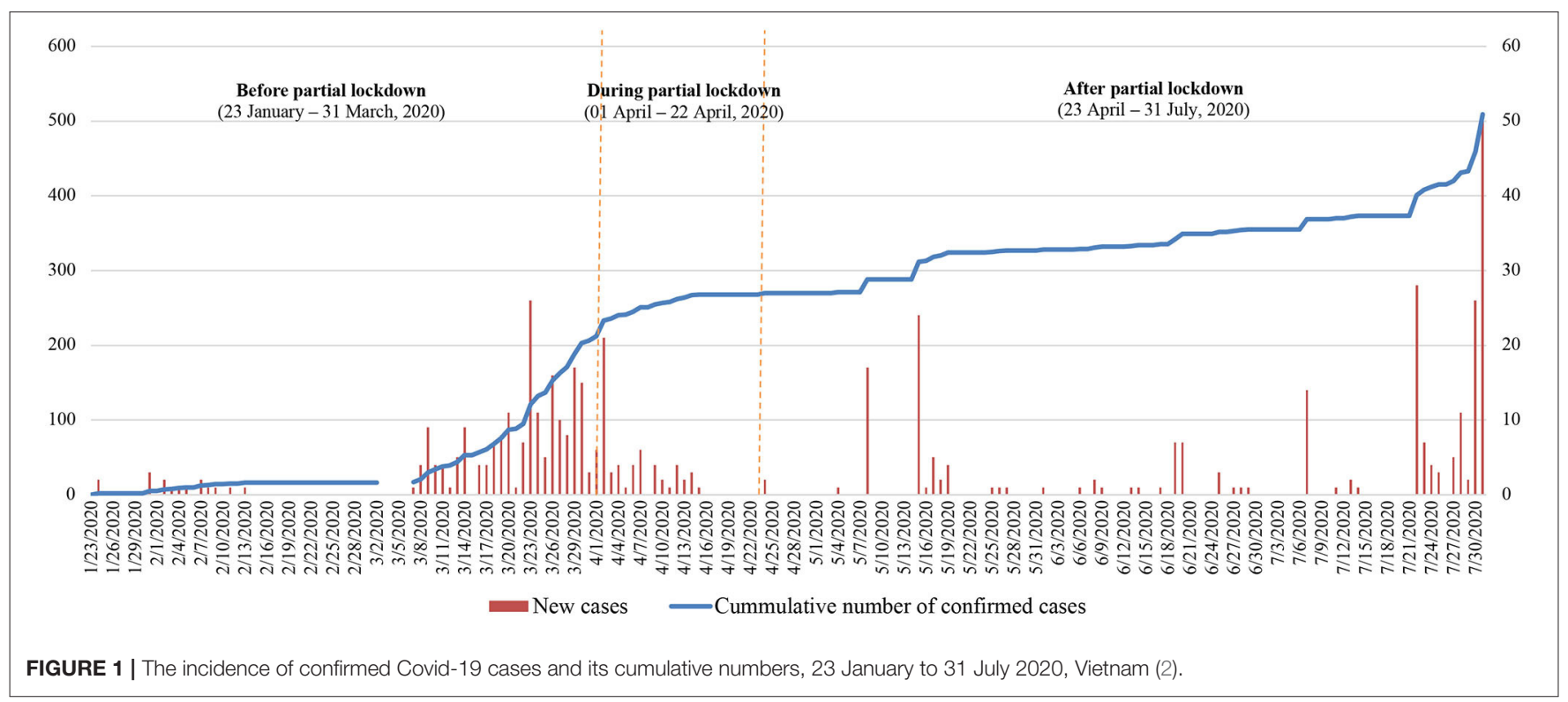

supported the Task Force to quickly decide the key directions for combating COVID-19, in which social distancing measures had a central role (6). Thus, Directive 06/CT-TTg, Directive 16/CTTTg, and Directive 19/CT-TTg were issued which underlined the social distancing measure implementation to prevent the spread of COVID-19 by maintaining physical distance and reducing social interactions. Moreover, local authorities issued regulations to guide and enforce social distancing in their community. As per these regulations, people not following social distancing recommendations such as going out in unnecessary cases and fleeing from isolation areas or quarantine facilities have to face administrative sanctions. On the other hand, the government maintained and resuscitated economic activity by encouraging Vietnamese businesses to transition to remote work. A continued support system in the provision of essential services and supplies was suggested by the government, aimed to facilitate adherence to social distancing measures for people and communities. People also received daily messages from the Government via mobile phones or mass media to motivate them to adhere to social distancing. In addition, the government protected people from being exposed to fake news about COVID-19 and the effects of social distancing by providing clear and transparent information about COVID-19 in Vietnam (7).

Adherence to social distancing can also be justified by the attributes of Vietnamese people. Recent evidence from a global survey showed that Vietnamese people were highly satisfied with and believed in the government's measures in the prevention and control of COVID-19 (8). This result might be achieved by various activities of the government as discussed above, including the assurance of essential goods during social distancing, clearing of COVID-19 risk communication, and prompting of actions to control the epidemic. Moreover, the prior experience with severe infectious epidemics (e.g., SARS, H1N1) helped people to understand the importance of social distancing in reducing the transmission rate. On top of that, Vietnamese culture might primarily contribute to the success of the social distancing approach in Vietnam. In fact, Confucianism determines the core values of Vietnamese society regarding different aspects such as philosophy, social organization, culture, and economy (9). This influence embraces the individuals' social responsibilities in protecting the health and life of other people in their community over their freedom or liberties (10), which are much different from Western culture. Living with this ideology facilitated the Vietnamese to respond to the COVID-19 epidemic in a solidarity way, that people altogether adhered to the social distancing to mitigate the impacts of COVID-19 (11).

Despite the more and more increasing global Covid-19 patient number with the overload of the health system, Vietnam has still been responding well to the Covid-19 pandemic with the mobilization of the entire political system. We understand that it is very difficult to implement high-level Covid-19 containment measures in the current phase as in the previous phase. In the "new normal" condition after the national lockdown strategy, one of the biggest future challenges we would like to emphasize is the indifference and subjectivity of the people in the prevention and control of COVID-19. Therefore, all ministries, sectors, organizations, and society from central to local levels need to harmoniously combine administrative and specialized solutions to suggest prompt and efficient actions in the worst-case scenarios in Vietnam.

In resource-constrained settings like Vietnam, strategies to promote aggressive social distancing should be based on the effectiveness analysis of this measure in different locations. The elements from the government and from the public contributing to the good compliance with social distance need to be further assessed to reflect each locality's situation. Importantly, in the "new normal" condition after COVID-19, compliance with social distancing in Vietnam 
will be effective when the measures to closely control and monitor repatriation and immigration via its borders are prioritized.

\section{AUTHOR CONTRIBUTIONS}

H-LV conceptualized the manuscript. HN reviewed and edited for the final manuscript. All authors synthesized data and related

\section{REFERENCES}

1. CDC. Social Distancing. (2020) Available online at: https://www.cdc. gov/coronavirus/2019-ncov/prevent-getting-sick/social-distancing.html (accessed July 27, 2020).

2. Pollack T, Thwaites G, Rabaa M, Choisy M, van Doorn R, Luong $\mathrm{DH}$, et al. Emerging COVID-19 Success Story: Vietnam's Commitment to Containment. (2020). This article is one of a series focused on identifying and understanding Exemplars in the response to the Coronavirus pandemic. It is hosted by the Exemplars in Global Health (EGH) platform]. Available online at: https://ourworldindata.org/covid-exemplar-vietnam (accessed July 27, 2020).

3. Prime Minister. 06/CT-TTg: Strengthening Preventive and Control. Measures Against New Complications of Acute Respiratory Infections Caused by New Strains of Corona Virus. Hanoi (2020).

4. Tuan D. The Prime Minister agreed to continue implementing Directive 16 at least until April 22 in Some localities Government Electronic Newspaper Government Portal. (2020) Available from: http://baochinhphu.vn/Tin-noibat/Thu-tuong-nhat-tri-tiep-tuc-thuc-hien-Chi-thi-16-it-nhat-den-224tai-mot-so-dia-phuong/393140.vgp (accessed July 28, 2020).

5. Vu K, Nguyen P, Pearson J. After Aggressive Mass Testing, Vietnam Says It Contains Coronavirus Outbreak: Reuters. (2020) Available online at: https:// www.reuters.com/article/us-health-coronavirus-vietnam-fight-insi/afteraggressive-mass-testing-vietnam- says-it-contains-coronavirus-outbreakidUSKBN22B34H (accessed July 28, 2020).

6. Prime Minister. Directive No. 16 / CT-TTg of the Prime Minister: On the Implementation of Urgent Measures to Prevent and Combat COVID-19 Epidemic. Hanoi (2020). information, wrote the manuscript, and have read and agreed to the published version of the manuscript.

\section{FUNDING}

This research was supported by Vingroup Innovation Foundation (VINIF) in project code VINIF. 2020.COVID-19.DA03.

7. Ministry of Health of Vietnam. Prime Minister: Communication Contributes to the Victory of the COVID-19 Campaign. (2020) Available online at: https://ncov.moh.gov.vn/-/thu-tuong-truyen-thong-gop-phan-lam-nenthang-loi-cua-cuoc-chien-chong-dich-covid- 19 (accessed July 27, 2020).

8. World Health Organization. Coronavirus Disease (COVID-19) Advice for the Public. (2020) Available online at: https://www.who.int/emergencies/diseases/ novel-coronavirus-2019/advice-for-public (accessed April 12, 2020).

9. Truong TD, Hallinger P, Sanga K. Confucian values and school leadership in Vietnam: Exploring the influence of culture on principal decision making. Educ Manag Administ Leadership. (2017) 45:77-100. doi: $10.1177 / 1741143215607877$

10. Hu Y. Prioritizing Human Rights Helps China Defeat Covid-19. Experts: Global Times (2020). Available online at: https://www.globaltimes.cn/content/ 1188066.shtml (accessed July 27, 2020).

11. Huynh TLD. The COVID-19 containment in Vietnam: what are we doing? $J$ Global Health. (2020) 10:010338. doi: 10.7189/jogh.10.010338

Conflict of Interest: The authors declare that the research was conducted in the absence of any commercial or financial relationships that could be construed as a potential conflict of interest.

Copyright (c) 2020 Vo, Nguyen, Nguyen, Nguyen, Nguyen, Nguyen, Vu and Le. This is an open-access article distributed under the terms of the Creative Commons Attribution License (CC BY). The use, distribution or reproduction in other forums is permitted, provided the original author(s) and the copyright owner(s) are credited and that the original publication in this journal is cited, in accordance with accepted academic practice. No use, distribution or reproduction is permitted which does not comply with these terms. 